\title{
FIRELESS, BURNING SMELL DRIVEN, MAYDAY LANDINGS OF COMMERCIAL AIRCRAFT AS A MECHANISMS OF MOTION IN MIRCE MECHANICS
}

\author{
Jezdimir Knežević* \\ MIRCE Akademy, Woodbury Park, Exeter, UK
}

According to Knezevic the purpose for the existence of any functionable system is to do functionability work'. The work is done when the expected measurable function is performed through time. However, experience teaches us that expected work is frequently beset by the occurrences of undesirable interruptions like component failures, natural phenomena or human actions, some of which result in hazardous consequences. MIRCE Mechanics is a body of knowledge that focuses on the scientific understanding and description of the mechanisms that generate undesirable in-service interruptions. Thus, the main objective of this paper is to examine the mechanism that generated undesirable in-service interruption to 32 flights, on 16th October 2017, within UK airspace. After fireless burning smoke/fumes were felt in their cockpits the flight crew went to oxygen and declared either a PAN-PAN or a MAYDAY landing. The first event took place around 0622 during departure from Liverpool causing the aircraft to declare mayday landing and return back to land. It was followed by clusters of affected aircraft in the Channel Islands, Liverpool, Manchester and London, later in the day. Although this is one of an extremely rear observed event, its mechanism had to be understood, as if repeated, it will generate the motion of an aircraft through MIRCE Functionability Field and impact its functionability work done and resources consumed. Inspections of aircraft involved and the analysis of the meteorological conditions in Europe have revealed that the burning smell did not result from a failure of any component, but it was as a result of smoke and dust carried in the atmosphere from North Africa and Iberia. Satellite imagery from the European Organisation for the Exploitation of Meteorological Satellites ${ }^{2}$ (EUMETSAT) verified this theory. Potencial actions for reducing the impact of this functionability mechanism are presented.

Key words: Aircraft, motion, MIRCE Mechanics

\section{INTRODUCTION}

The philosophy of MIRCE Science is based on the premise that the purpose for the existence of any functionable system is to do functionability work. The work is done when the expected measurable function is performed through time. [1] However, experience teaches us that expected work is frequently beset by the occurrences of undesirable interruptions like component failures, natural phenomena or human actions, some of which result in hazardous consequences.

"Mayday" is the word used around the globe to make a distress call via radio communications. Mayday signals a life-threatening emergency, usually on a ship or an aircraft, although it may be used in a variety of other situations. It originated as an international distress call in 1923 and was made official in 1948. "Mayday" was the idea of Frederick Mockford, who was a senior radio officer at Croydon Airport in London, England. He came up with the idea for "mayday" because it sounded like the French word "m'aider", which means "help me."
A typical international distress call starts with the word "mayday" repeated three times, not to be mistaken for another word or phrase that sounds similar under noisy and stressful conditions. It is followed by all the relevant information that potential rescuers would need, including type and identity of craft involved, nature of the emergency, location or last known location, current weather, fuel remaining, what type of help is needed and number of people in danger.

A mayday call is not something to be taken lightly. In the United States, it is illegal to make a fake distress call. Unjustified use carries a jail sentence for up to six years and is subject to a $\$ 250,000$ fine!

For situations that are less than life-threatening, one of several other urgent messages can be conveyed. For example, "Pan-Pan", from the French word "panne", which means "breakdown", can be used to signal an urgent situation involving a mechanical or medical issue.

Thus, the main objective of this paper is to examine the mechanisms that generated undesirable in-service interruption to 32 flights, on 16th October 2017, within UK

\footnotetext{
${ }^{1}$ According to Knezevic [1], functionable system type is "a set of mutually related entities put together to do a functionability work in accordance to physical laws and given functionability rules"

${ }^{2}$ EUMWTSAT in an intergovernmental organisation created through an international convention agreed by a current total of 30 European Member States
} 
airspace. After fireless burning smoke/fumes were felt in a cockpit the flight crew went on oxygen and declared either a PAN-PAN or a MAYDAY landing. The first event took place around 0622 during departure from Liverpool causing the aircraft to declare mayday landing and return back to land. It followed by clusters of affected aircraft in the Channel Islands, Liverpool, Manchester and London, later in the day.

Although this is one of an extremely rare observed event, its mechanism had to be understood, as it generate the motion of an aircraft through MIRCE Functionability Field and impacts the functionability work done by an aircraft and resources consumed during its in-service life. The final analysis confirmed that the burning smell was not resulting from a failure of components of aircraft involved, but from smoke and dust carried in the atmosphere from North Africa and Iberia.

\section{MIRCE SCIENCE FUNDAMENTALS}

Undoubtedly, the ability to accurately and quantitatively predict the probability of occurrences of in-service undesirable interruptions, especially those with hazardous consequences, early in the design stage would be invaluable for all decision makers.

Regardless of whether engineering solutions or management methods are chosen to control the occurrences of in-service undesirable interruptions, they will have a direct impact on the business plan that should deliver the expected work, within the expected budget and generate the expected return on their investment (e.g. profit, reputation, loyalty, public benefit and similar).

Consequently, Dr Knezevic [1] has created the body of knowledge, named MIRCE Science ${ }^{3}$, that can be used for the quantitative prediction of the probability of occurrences of undesirable interruptions during the expected in-service life of any given functionability system type. According to MIRCE Science, at any instant of calendar time, a given functionable system type could be in one of the following two states [1]:

- Positive Functionability State (PFS), a generic name for a state in which a functionable system type is able to deliver the expected measurable function(s),

- Negative Functionability State (NFS), a generic name for a state in which a functionable system type is unable to deliver the expected measurable function(s), resulting from any reason whatsoever.

In MIRCE Science functionability work done by a functionable system type is uniquely defined by the trajectory generated by its motion through the MIRCE Functionability Field 4 (MFF). The motion of a functionable system type through the MFF is driven by functionability actions, which are classified as:

- Positive Functionability Action (PFA), a generic name for any human activity or physical phenomena that compels a system to move to a PFS.

- Negative Functionability Action (NFA), a generic name for any physical phenomena or human activity that compels a system to move to a NFS.

The motion of a functionable system type through the MFF is physically manifested through the occurrences of functionability events, which are classified as:

- Positive Functionability Event (PFE), a generic name for any physically observable occurrence in the calendar time that signifies the transition of a functionable system type from a NFS to a PFS.

- Negative Functionability Event (NFE), a generic name for any physically observable occurrence in the calendar time that signifies the transition of a functionable system type from a PFS to a NFS.

MIRCE Mechanics is a part of MIRCE Science that focuses on the scientific understanding of the mechanisms that generate functionability action, which govern the motion of functionable system types though MFF [1]. The occurrences of undesirable interruptions are considered within a physical scale between $10^{-10}$ (atomic system) and $10^{10}$ (solar system) of a metre. These mechanisms, together with the corresponding functionability rules imposed by humans shape the pattern of the occurrences of these undesirable interruptions through MIRCE Functionability Field. The life-long pattern expected to be generated by each future functionability system type is predictable, from the early stages of the design, by making use of the MIRCE Functionability, Operability, Maintainability and Supportability Equations [2, 3].

\section{MONDAY 16 OCTOBER 2017}

\section{Dublin Airport, Ireland}

An Embraer 190 passenger aircraft, G-FBEM, took off from Cardiff Airport (EGFF) in Wales at 0614 for a scheduled passenger flight to Dublin Airport (EIDW) in Ireland with 75 passengers and a crew of five. The climb, enroute and initial descent flight phases were routine. [4]

At 0635, the aircraft was cleared for landing on Runway 10. Due to a low-visibility weather conditions the crew were instructed to hold at FL 090. At 0706, Air Traffic

\footnotetext{
${ }^{3}$ MIRCE Science comprises of mathematical axioms, equations and methods that enable predictions of expected functionability performance of each feasible option of the future functionability system type to be done, based on the complex, time-dependent, interactions between: physical properties of consisting components and applied functionability rules regarding operation, maintenance and support processes.

${ }^{4}$ MFF is mathematically described as a two dimensional countable infinite set of possible functionability points, each representing functionability state that a functionable system type could be found in, at any instant of the calendar time. [1]
}

$$
\operatorname{MFF}_{S}(t)=\left\{\operatorname{PFS}_{S}^{i-1}(t), N F S_{S}^{i}(t), t>0, i=1,2, ., \infty\right\}
$$


Control (ATC) cleared the aircraft to leave the holding pattern and continue on to Runway 10. Weather at Dublin included light rain and drizzle with scattered clouds at $100 \mathrm{ft}$. and a broken layer at $200 \mathrm{ft}$. Visibility was 3,500 meters.

As the aircraft departed the holding pattern, it entered the top of a cloud layer and the flight crew noticed a burning smell, which they described as "sulphurous" and similar to that of "burning wood or paper." As the captain had experienced similar odours before his first thought was that it might be originating from the aircraft oven. He contacted the senior cabin crewmember to check if "everything was OK" in the cabin. In response he was told that that the ovens were not the source but the attendants could detect a burning smell in the rear of the cabin. The captain informed the co-pilot that there was a "smell of smoke in the cabin" and both pilots noted that the smell appeared to be getting more intense in the cockpit, although no crewmember saw smoke at any time during the flight.

Without any hesitation, both pilots donned their oxygen masks and at 0713, and declared a PAN-PAN ${ }^{5}$. ATC immediately gave priority to the flight and cleared it directly to the final approach to Runway 10. At 0714, the aircraft was cleared to descend to 4,000 ft. and the captain conducted the ILS ${ }^{6}$ approach to Runway 10 with the autopilot engaged. He acquired the runway visual references at approximately $300 \mathrm{ft}$. $\mathrm{AGL}^{7}$ and took over manual control for landing. The aircraft rolled out at 0723 and was met by the airport fire services after it cleared the active runway. The emergency crew informed the captain that there appeared to be no signs of fire or damage on the exterior of the aircraft.

The flight crew removed their oxygen masks and noted that the smell of smoke had been reduced. The captain then asked the cabin crew for an assessment of conditions in the cabin and was told that the smell of smoke had lessened. With no obvious threat to safety, at 0731, the flight crew requested taxi clearance to their parking position and disembarked their passengers normally. [4]

\section{Manchester Airport, England}

\section{EasyJet}

\section{Alicante - Manchester Flight}

An EasyJet flight that was heading towards Manchester Airport from Alicante, Spain, had been forced to declare Mayday emergency landing because of the smoke smells coming from the cockpit. After landing at Manchester
Airport the aircraft was surrounded by fire engines as it reached Terminal 1, while airport train services were temporarily stopped for safety reasons. [6]

The aircraft landed safely. One of the passengers said, "There was a definite smell of smoke." [6]

\section{Manchester - Hamburg}

Flight EasyJet flight EZY1841 was scheduled to fly from Manchester Airport to Hamburg at 12:25. The flight was airborne for about 20 minutes when the captain detected "smoke in the cockpit" and decided to return to Manchester. [8]

Passengers in the cabin also caught a whiff of the smoke, which "smelled like a firework". They were escorted away from the plane by fire crews, before being put back on the same plane for departure. [8]

\section{Flybe}

A scheduled passenger flight from Cardiff to Dublin took "precautionary action" and landed at Manchester airport after the crew detected the smell of fumes.

Flyby also confirmed that a scheduled flight from Manchester to Paris was returned due to a "fume-like smell", felt by the flying crew in the cockpit. [7]

\section{Jet2}

Jet2, a British low cost charter and scheduled airline, aircraft was unable to land at Leeds Airport due to foggy conditions. After circling several times over Leeds the crew decided to land at Manchester Airport instead.

The landing was safe and "unadventurous".

\section{Liverpool Airport, England}

The EasyJet flight EZY 7159 from Liverpool John Lennon (LPL) to Zakynthos took off on time towards the scheduled destination that was International Dionysios Solomos (ZTH) in Greece. [7]

Soon after take off the flight crew noticed a "burning smell" in the cockpit. Immediately, the pilot turned the plane around and requested an emergency landing at John Lennon airport. ATC provided the crew with all information necessary for an emergency landing. After the safe landing the aircraft examination showed no signs of any possible source of "burning smell".

Another EasyJet flight declared "full emergency" landing at Liverpool Airport. All flights landed normally to LPL without the assistance of emergency services which were just a precautionary measure.

\footnotetext{
${ }^{5}$ The radiotelephony message PAN-PAN is the international standard urgency signal that someone aboard a boat, ship, aircraft, or other vehicle uses to declare that they have a situation that is urgent, but for the time being, does not pose an immediate danger to anyone's life or to the vessel itself

${ }^{6}$ Instrument Landing System (ILS) is defined as a precision runway approach aid based on two radio beams which together provide pilots vertical and horizontal guidance during an approach to land.

${ }^{7}$ In aviation, atmospheric sciences and broadcasting, a height above ground level (AGL) is a height measured with respect to the underlying ground surface. This is as opposed to altitude/elevation above mean sea level (AMSL), or (in broadcast engineering) height above average terrain (HAAT).
} 
A spokesman for EasyJet said: "EasyJet can confirm that four of its flights flying in the west of the UK had reported smoke smells in the cockpit that day! [7]

\section{Guernsey Airport}

Aurigny Air Services aircraft that was travelling from Guernsey to Bristol had to head back to the Channel Island due to a smell detected by the cockpit crew. It was returned to service after post-flight checks by engineers. [10]

\section{Jersey Airport}

Emergency services were called to a British Airways aircraft landing in Jersey "as a precaution" due to the conditions. [10]

\section{Hawarden Airport, Chester, England}

During a descent of Jetstream 4100, G-MAJC, into Hawarden Airport, at around FL150, the flight crew noticed a burning smell. Oxygen masks were donned, a Mayday was declared and an expedited approach was carried out to land on Runway 22. The crew experienced some difficulty in communication, both internal and external, while using their oxygen masks. [5]

After landing the aircraft was taxied clear of the runway, brought to a stop, and an emergency evacuation was carried out. [5]

\section{At the End of the Day}

NATS, formerly National Air Traffic Services ${ }^{8}$, is the UK's leading provider of air traffic control services that handles 2.4 million flights and 250 million passengers in UK airspace, each year. In addition to providing services to 14 UK airports, and managing all upper airspace in the UK, NATS provides services around the world spanning Europe, the Middle East, Asia and North America.

On 16th October 2017 NATS facilitated "a number" of diversions from aircraft reporting fumes being detected in the cockpit. All of these flights had landed safely.

It came following reports of an "unusual" reddish sky across parts of England, which experts are attributing to the remnants of Hurricane Ophelia dragging in tropical air and dust from the Sahara.

\section{THE SOURCE OF FIRELESS BURNING SMELL}

The investigators of the Embraer SA, G-FBEM, were informed by the UK Air Accident Investigation Board (AAIB) that the smoke/fumes were detected from between 2,000 ft. and FL 200, and that most of the aircraft either returned to land at the point of departure or expedited their existing approaches. [4]

It turned out that, between Oct. 13 and 18, up to 8,000 $\mathrm{ft}$ wildfires were burning across northern Portugal and north-western Spain. Hurricane Ophelia ${ }^{9}$ was passing by offshore, fanning the fires and pushing the smoke northward along with its own path.

Ireland's weather service said later that "the sheer scale of the wildfires in that area meant that the air quickly became highly concentrated with dense smoke. With this being the source area for the air mass over Dublin at $0700 z$ and the strong winds dragging this air quickly northward, it is not surprising that the smoke was dense enough to register in the cockpits of commercial aircraft flying at the time."

Based on the above information the Irish air safety investigators concluded "it is clear that the detection of smoke on numerous commercial aircraft on that date can be attributed to the rapid advection of air laden with particulates from Iberian wildfires northward over Ireland and the UK by Ophelia." [3, 7, 8]

\section{UK Met office Report on 17th October 2017}

The Met Office ${ }^{10}$ on 17th October 2017 reported that, the same southerly winds that had brought the current warmth had also drawn dust from the Sahara and smoke from wildfires occurring over northern Iberia (Spain/ Portugal) to our latitudes. [10] Ophelia originated in the Azores where it was a hurricane and as it tracked its way northwards it dragged in tropical air from the Sahara. The dust gets picked up into the air and goes high up into the atmosphere, and that dust has been dragged high up in the atmosphere above the UK. The particles in the air cause blue light to scatter, leaving longer-wavelength red light to shine through. [11]

\section{EUMETSAT Confirmation}

Satellite imagery from the European Organisation for the Exploitation of Meteorological Satellites ${ }^{11}$ (EUMETSAT) verified this theory. [9]

\footnotetext{
${ }^{8}$ Established in 1962 to bring together responsibility for the UK's existing military and civil Air Traffic Control services.

${ }^{9}$ Hurricane Ophelia was regarded as the worst storm to affect Ireland in 50 years, and was also the easternmost Atlantic major hurricane on record. Total fatalities: 54 , Highest wind speed: $185 \mathrm{~km} / \mathrm{h}$

Date: 9 October 2017 - 18 October 2017, Start date: 16 October 2017, 1:28 pm BST, estimated damage over \$65.3 million (2017 USD). Affected areas: France, United Kingdom, Spain, Portugal, Ireland, Sweden, Finland, Azores, Scandinavia

${ }^{10}$ The Met Office was established in 1854 as a small department within the Board of Trade under Vice Admiral Robert FitzRoy as a service to mariners.

${ }^{11}$ EUMWTSAT in an intergovernmental organisation created through an international convention agreed by a current total of 30 European Member States,
} 


\section{WHAT COULD BE DONE?}

Although the same smoke from wildfires on the Iberian Peninsula drawn toward Ireland and the UK caused all emergency landings in very short interval of time the participating cabin crew and ATC of the affected airports were not informed about the existing atmospheric conditions. Hence, it is reasonable to ask should any formal system be established to notify flight crew of the presence of smoke in the atmosphere from ground fires.

\section{Pilots Demand New Cabin Air Filters on Commercial Aircraft}

Following "Fireless, Burning Smell Driven, Mayday Landings of Commercial Aircraft" on 16th October 2017, the British Airline Pilots Association (BALPA) wrote to regulators to ask that "effective filters are developed and are then required to be fitted." [12]

Dr Hunter, head of flight safety of BALPA said: "Today we have seen high levels of contaminants in the air, which experts are attributing to the remnants of Hurricane Ophelia dragging tropical air and dust from the Sahara, as well as debris from forest fires in Portugal and Spain. A vulnerability of the way in which cabin air is supplied in most airliners is that there is no direct filtration of the outside air before it enters the cabin, so if the outside air is contaminated, this contaminated air is drawn into the aircraft. This most commonly happens when an aircraft is taxiing on the ground close to the jet exhaust of another aircraft and it is rare for the atmosphere to be contaminated at cruising altitude. However, contamination can occur when there are high levels of atmospheric pollution, when volcanic ash and volcanic gasses are in the atmosphere and when dusts from storms or soot from fires on the ground are drawn in to the air." [12]

As of now, March 2019, the author could not find any information regarding the response from the Aviation authorities to the BALPA's request for "the effective filters are developed and are then required to be fitted."

\section{Inclusion of Information to flight crews on the presence of smoke in the atmosphere from ground fires in SIGNET ${ }^{12}$}

The Irish Air Accident Investigation Unit (AAIU) investigators pointed out that $\mathrm{ICAO}^{13}$ standards and recommendations for SIGMETs list thunderstorms, cyclones, severe turbulence, severe icing, severe mountain waves, dust or sand storms, and volcanic ash, but there is no requirement to include the presence of large quantities of smoke in the atmosphere. [4]

\section{SIGMET}

A SIGMET provides concise information issued by a Meteorological Watch Office (MWO) concerning the occurrence or expected occurrence of specific en-route weather and other phenomena in the atmosphere that may affect the safety of aircraft operations.

There three types of SIGMET, as shown in the table below.

Table 1: Three types of SIGMET

\begin{tabular}{|l|l|l|}
\hline \multicolumn{1}{|c|}{ SIGMET (WS) } & SIGMET (WV) & SIGMET (WC) \\
\hline TS: Thunderstorm & VA: Volcanic ash & $\begin{array}{l}\text { TC: Tropical } \\
\text { cyclone }\end{array}$ \\
\hline TURB: Turbulence & & \\
\hline ICE: Icing & & \\
\hline $\begin{array}{l}\text { MTW: Mountain } \\
\text { wave }\end{array}$ & & \\
\hline DS: Duststorm & & \\
\hline SS: Sandstorm & & \\
\hline
\end{tabular}

SIGMETs (WSs) are inflight advisories concerning non-convective weather that is potentially hazardous to all aircraft. They report weather forecasts that include severe icing not associated with thunderstorms, severe or extreme turbulence or clear air turbulence not associated with thunderstorms, dust storms or sandstorms that lower surface or inflight visibilities to below three miles, and volcanic ash. SIGMETs are unscheduled forecasts that are valid for 4 hours, but if the SIGMET relates to hurricanes, it is valid for 6 hours.

Phenomena reported by SIGNET (WS) are shown in the table 2.

\section{The Recommendation to ICAO}

As of March 2019, the author could not find any information regarding the Irish Air Accident Investigation Unit's recommendation to ICAO to consider the provision of including the information to flight crews of the presence of smoke in the atmosphere from ground fires and prevent all of those unnecessary Mayday calls and use of safety resources associated with each emergency landings.

\section{CONCLUSIONS}

Thus, the main objective of this paper is to examine the physical mechanism of an undesirable flight interruption

\footnotetext{
${ }^{12}$ Significant Meteorological Information is a weather advisory that contains meteorological information concerning the safety of all aircraft.

${ }^{13}$ The International Civil Aviation Organization (ICAO; French: Organisation de l'aviation civile internationale) is a specialised agency of the United Nations. It codifies the principles and techniques of international air navigation and fosters the planning and development of international air transport to ensure safe and orderly growth. Its headquarters is located in Montreal, Canada.
} 
Table 2: Phenomena reported by SIGNET (WS)

\begin{tabular}{|l|l|}
\hline \multicolumn{1}{|c|}{ Code } & \multicolumn{1}{c|}{ Description } \\
\hline OBSC TS & Obscured thunderstorms \\
\hline EMBD TS & Embedded thunderstorms \\
\hline FRQ TS & Frequent thunderstorms \\
\hline SQL TS & Squall line thunderstorms \\
\hline OBSC TSGR & Obscured thunderstorms with hail \\
\hline EMBD TSGR & Embedded thunderstorms with hail \\
\hline FRQ TSGR & Frequent thunderstorms with hail \\
\hline SQL TSGR & Squall line thunderstorms with hail \\
\hline SEV TURB & Severe turbulence \\
\hline SEV ICE & Severe icing \\
\hline SEV ICE (FZRA) & Severe icing due to freezing rain \\
\hline SEV MTW & Severe mountain wave \\
\hline HVY DS & Heavy duststorm \\
\hline HVY SS & Heavy sandstorm \\
\hline RDOACT CLD & Radioactive cloud \\
\hline $\begin{array}{l}\text { The SIGMET (VC) } \\
\text { ash phenomena and the SIGNET (WC) informs the } \\
\text { tropical cyclones. }\end{array}$ & \\
\hline
\end{tabular}

that had been experienced and recorded by 32 commercial flights on 16th October 2017, by a number of airlines, within UK airspace. When burning smoke/fumes were smelt in cockpits of affected flights flight crews went on oxygen and declared either a "pan-pan" or "mayday" landing. The first event had been experienced around 0622 during departure from Liverpool causing the aircraft to declare mayday landing and return back to land. It was followed by clusters of affected aircraft in the Channel Islands, Liverpool, Manchester and London, later in the day.

Although this was an extremely rare event, its mechanism had to be understood, as its occurrence generates the motion of an aircraft through MIRCE Functionability Field, which impacts the functionability work done and resources consumed during its in-service life. The fireless burning smell in cockpits of aircraft affected was not as a result of a failure of any component within aircraft, but by the smoke and dust carried in the atmosphere from North Africa and Iberia. Thus, this paper makes a clear distinction between the aircraft reliability widely covered in literature during the last 60 years and the aircraft functionability introduced and studied by MIRCE Science. While the former deals with probabilities of not having components and system failures within a given interval of time, the latter is dealing with a work done by a functionable system during its in-service life. Hence, the reliability performance of a system are a subset of the of the functionability performance of a system.

In response to the occurrence of this NFE the British Airline Pilots Association wrote to regulators to ask that "the effective filters are developed and are then required to be fitted," while the Irish Air Accident Investigation Unit's recommended to ICAO to consider the provision of including the information to flight crews of the presence of smoke in the atmosphere from ground fires and prevent all of those unnecessary mayday calls and use of safety resources associated with each emergency landing. However, the author was unable to fine any evidence of the implementation of either recommendation.

\section{REFERENCES}

1. Knezevic, J., The Origin of MIRCE Science, pp. 232. MIRCE Science, Exeter, UK, 2017, ISBN 9781-904848-06-6

2. Knezevic, J., MIRCE Functionability Equation, Journal of Engineering Research and Applications, ISSN: 2248-9622, Vol. 4, Issue 8( Version 1), August 2014, pp 93-100.

3. 2015 Annals of MIRCE Science, edited by J. Knezevic, pp 122, MIRCE Science, Exeter, UK, January 2016

4. Air Accident Investigation Unit Ireland, SYNOPTIC REPORT SERIOUS INCIDENT Embraer SA, ERJ 190-200 LR, G-FBEM, Dublin Airport, 16 October 2017

5. Emergency evacuation, Hawarden Airport, Chester, 16 October 2017, Air Accidents Investigation Branch, Investigation to Jetstream 4100, G-MAJC, Published 12 July 2018

6. Smallman , K., EasyJet flight from Spain forced to make emergency landing in UK due to storm Ophelia and Sahara dust, Euroweek, 17 October 2017

7. Smoke smell' forces flights to land at UK airports, BBC News, 16th October 2017 https://www.bbc. co.uk/news/uk-england-41639386 (accessed 26th January 2019)

8. EasyJet flights forced to make emergency landings due to Saharan dust which is turning sky orange, Manchester Evening News, 16 October 2017. https://www.manchestereveningnews.co.uk/news/ greater-manchester-news/easyjet-storm-ophelia-sahara-dust-13769779 (accessed 1st March 2019)

9. UK Aviation News, "Storm causing aircraft to make emergency landings due to "smoke", 16 October 2017 , https://ukaviation.news/storm-causing-aircraftto-make-emergency-landings-due-to-smoke/(accessed 11th February 2019) 
10. Murphy-Bates, S., 'Smoke smell' from the cockpit forces flights to land at UK airports due to 'atmospheric conditions' caused by Hurricane Ophelia, Mail on Line, 16th October 2017, https://www.dailymail.co.uk/news/article-4985904/Smoke-smellcockpit-forces-flights-land.html (accessed 27 February 2019)

11. Khomami, N., Apocalypse wow: dust from Sahara and fires in Portugal turn UK sky red, The Guardian, London, UK, Mon 16 Oct 201716.18 BST, https:// www.theguardian.com/uk-news/2017/oct/16/apocalypse-wow-saharan-dust-and-iberian-fires-turn-ukskies-red, (accessed 23 January 2019)
12. Davies, P., Pilots demand new cabin air filters on aircraft, Travel Weekly, 17 October 2018, UK http:// www.travelweekly.co.uk/articles/289916/pilots-demand-new-cabin-air-filters-on-aircraft (Accessed 6th February 2019) 